\title{
Photographs for anthropometric measurements of the breast region. Are there limitations?
}

\author{
Paulo Rogério Quieregatto ${ }^{\mathrm{I}}$, Bernardo Hochman', Fabianne Furtado ${ }^{\mathrm{III}}$, Soraia Francisco Ferrara ${ }^{\mathrm{IV}}$, Aline Fernanda Perez \\ Machadov, Miguel Sabino Neto $^{\text {VI }}$, Lydia Masako Ferreira ${ }^{\text {VII }}$
}

DOI: http://dx.doi.org/10.1590/S0102-8650201500700000010

IFellow Master degree, Postgraduate Program in Plastic Surgery, Universidade Federal de São Paulo (UNIFESP), Brazil. Conception, design, intellectual and scientific content of the study; acquisition, interpretation and analysis of data; manuscript preparation.

IIPhD, Affiliate Professor (in memoriam), Department of Surgery, UNIFESP, Sao Paulo-SP, Brazil. Conception, design, intellectual and scientific content of the study; interpretation and analysis of data; manuscript writing; critical revision.

IIIPhD, Affiliate Professor, Department of Surgery, UNIFESP, Sao Paulo-SP, Brazil. Conception and design of the study; acquisition, interpretation and analysis of data; manuscript writing; critical revision.

${ }^{\text {IV }}$ PT, MS, Physiotherapist, Private Practice, Sao Paulo-SP, Brazil. Conception and design of the study, acquisition of data, manuscript writing.

${ }^{v}$ Fellow Master degree, Postgraduate Program in Translational Surgery, UNIFESP, Sao Paulo-SP, Brazil. Interpretation and analysis of data, manuscript writing.

${ }^{\mathrm{V}} \mathrm{PhD}$, Full Professor, Department of Surgery, UNIFESP, Sao Paulo-SP, Brazil. Conception, intellectual and scientific content of the study; interpretation and analysis of data; manuscript writing; critical revision.

VIIPhD, Full Professor, Department of Surgery, UNIFESP, Sao Paulo-SP, Brazil. Conception of the study, critical revision.

\section{ABSTRACT}

PURPOSE: To determine the limitations of the photographs used to obtain the anthropometric measurements of the breast region. METHODS: Five women, between the ages of 18 to 60 years, were evaluated. Photographs of the frontal and left and right profile views of their breasts were taken. Based on the current literature, the most commonly used anthropometric and anatomic landmarks for breast measurement were marked in their different positions. The different points were used to evaluate if the direct anthropometry was possible in a standardized way and determine how the points and the positions can to be used in any breast measurements.

RESULTS: There were some limitations to the use of defining points of the breast fold, as well as of its lower portion and lateral extension positions in both profiles.

CONCLUSION: The defining points of the breast fold and the profile photographs have some limitations and we suggested how the points and positions can be used for breasts measurements.

Key words: Anthropometry. Breast. Body Weight and Measures. Mammaplasty. Thorax. 


\section{Introduction}

The study of the structure of the female breast is important in clinical practice to define the best surgery technique to be used ${ }^{1}$. At the same time, the patient feels the need to be informed in advance about the asymmetries to minimize some unrealistic expectations of the surgery outcomes ${ }^{2}$. The standard photographic documentation has been used as a tool, becoming a source of scientific information for any evaluation ${ }^{3}$.

Direct and indirect anthropometry are two different measurement methods used for breast evaluation. Direct anthropometric measurements can be taken from the patient in a clinical setting, using linear measures and anthropometric points. Indirect anthropometry is a technique used for measuring photographs or images. The analysis of these images can be performed using software tools that have their own calibration made either by linear markers or pixels and provides realtime data without the physical presence of a patient ${ }^{4}$.

The use of photographs not only provides a preoperative registry data but also has greater advantages over direct anthropometry as it reduces the patient's discomfort, allows measurements (and re-measurements) at any time and enables centesimal precision provided by the graphics software tools ${ }^{4}$.

For female breast evaluation, significant aspects are considered, such as differences in volume, surface area, and contour, which are difficult to be measured accurately using a preset protocol $^{5}$. Several authors have determined some reference parameters for esthetically perfect breasts ${ }^{6-10}$. Moreover, these authors have established values for breast positioning, volume and shape using linear and reproducible measures that are applied to the general population. These studies have also identified the factors that influenced the changes of these measurements such as weight, age, pregnancy, lactation and biotype.

Computerized photogrammetry could be more efficient and less intrusive for the patient and contribute to a more objective analysis of the postoperative results, especially after mastoplasty.
Quieregatto et al. ${ }^{11}$ found differences between the tape and compass measurements of volunteers evaluated by direct anthropometry. In this study, the authors marked the patient's anatomic points in frontal view only.

Sivagnanavel et al. ${ }^{12}$ and Assunção et al. ${ }^{13}$ have proposed software validation studies to achieve comparable measurements. Although the authors used the same computer-aided tools and theoretical basis, the results could have been different.

The present study aimed to describe the difficulties found in determining the points using indirect anthropometric measurements of the breast.

\section{Methods}

The research was approved by the Institutional Research Ethics Committee (approval number CEP 1054/10). Written informed consent was obtained from all participants prior to their inclusion in the study and anonymity was ensured.

Five volunteers with different types of breast and different ages were selected for the study. We attempted to identify the extremes related to the degrees of ptosis and hypomasty for a more comprehensive assessment. A total of 18 points were marked on the volunteers ' skin surface, then fotographs were taken of the frontal, right and left profiles of the patient placed in a standing position.

\section{Description of the search strategies for selection of the points}

An electronic search was performed in the MEDLINE database via PubMed, from 1966 until December 2013. The search strategy used was based on the descriptors presented above (Table 1). It was used in combination with the following terms:

In the articles selected from the literature review, 16 authors have described both anatomic and anthropometric measurement points of the breast region (Table 2) (-11,14-24 $^{6}$ 


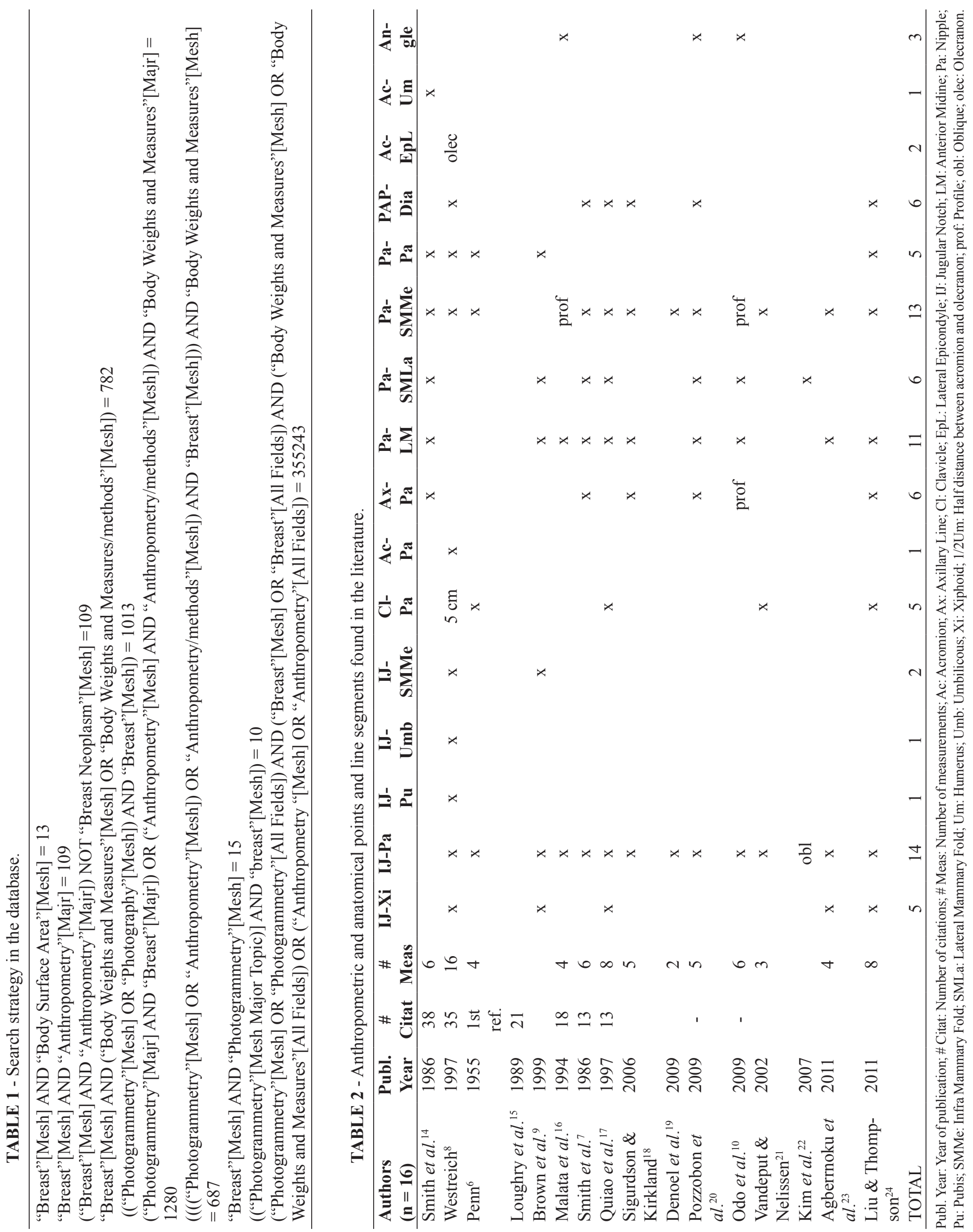


Eighteen points were selected: mid-portion of the breast fold (MPBF), lateral portion of breast fold (LPBF), Umbilicus (U) and pubis $(\mathrm{Pu})$, the central portion of the sternal notch (SN), basis of the xifoid process (Xi), the central portion of the breast papilla (CBP) right and left sides, acromion (AC) right and left sides, the anterior projection of the lateral epicondyle (LEP) right and left sides, half distance between the center of the sternal notch and the acromion, named as " $\mathrm{x}$ " point of the clavicle $(\mathrm{xCl})$ right and left sides, the proximal point of anterior axilla line $(\mathrm{Ax})$ right and left sides, and the half distance between the acromion and the lateral epicondyle, named as the mid-point of the humerus (1/2 Hum) right and left sides (Figure 1).

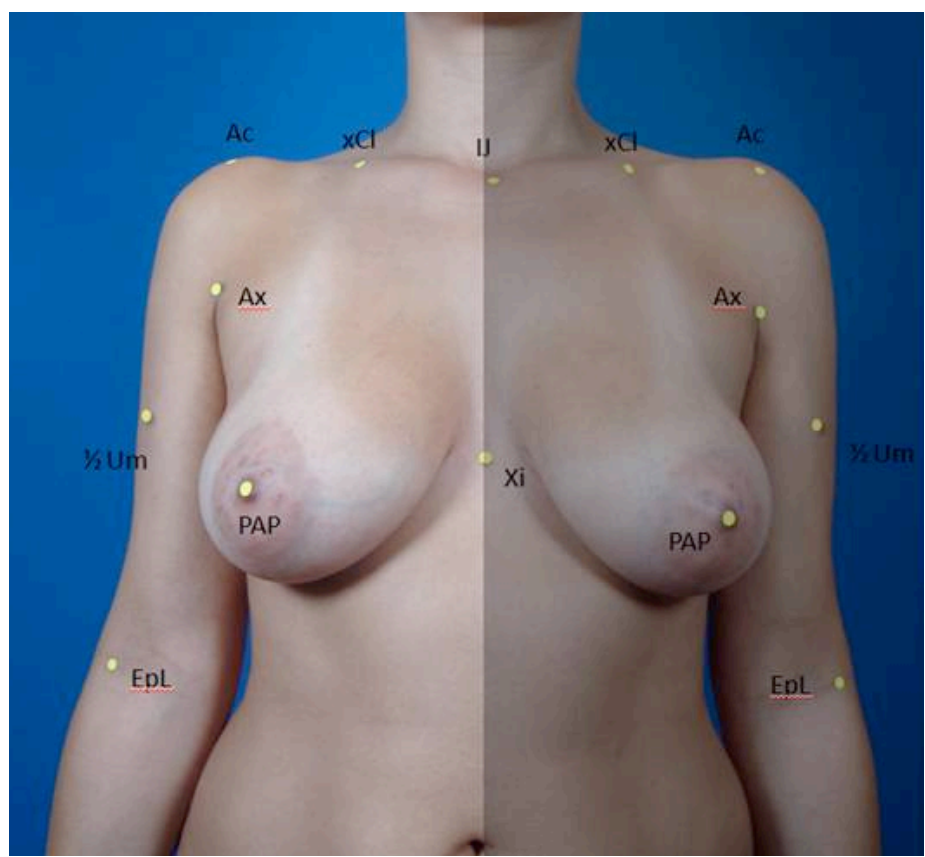

FIGURE 1 - Labeling of anatomic and anthropometric hemibody points, front view. Counterclockwise: $\mathrm{SN}=$ Central portion of the sternal notch; $\mathrm{xCl}=$ half distance between $\mathrm{SN}$ and the acromion; $\mathrm{Ac}=$ lateral prominence of the acromion; $\mathrm{Ax}=$ proximal point of anterior axillary line; $1 / 2 \mathrm{Um}=$ Half distance between acromion and olecranon; $\mathrm{EpL}=$ previous projection of the lateral epicondyle; $\mathrm{PAP}=$ Central portion of the breast papilla; $\mathrm{Xi}=$ basis of the xifoid process. Photographic image.

The transverse line of gnathion and the lower margin of the umbilicus were marked on the photographic image of the breast region (Figure 2).

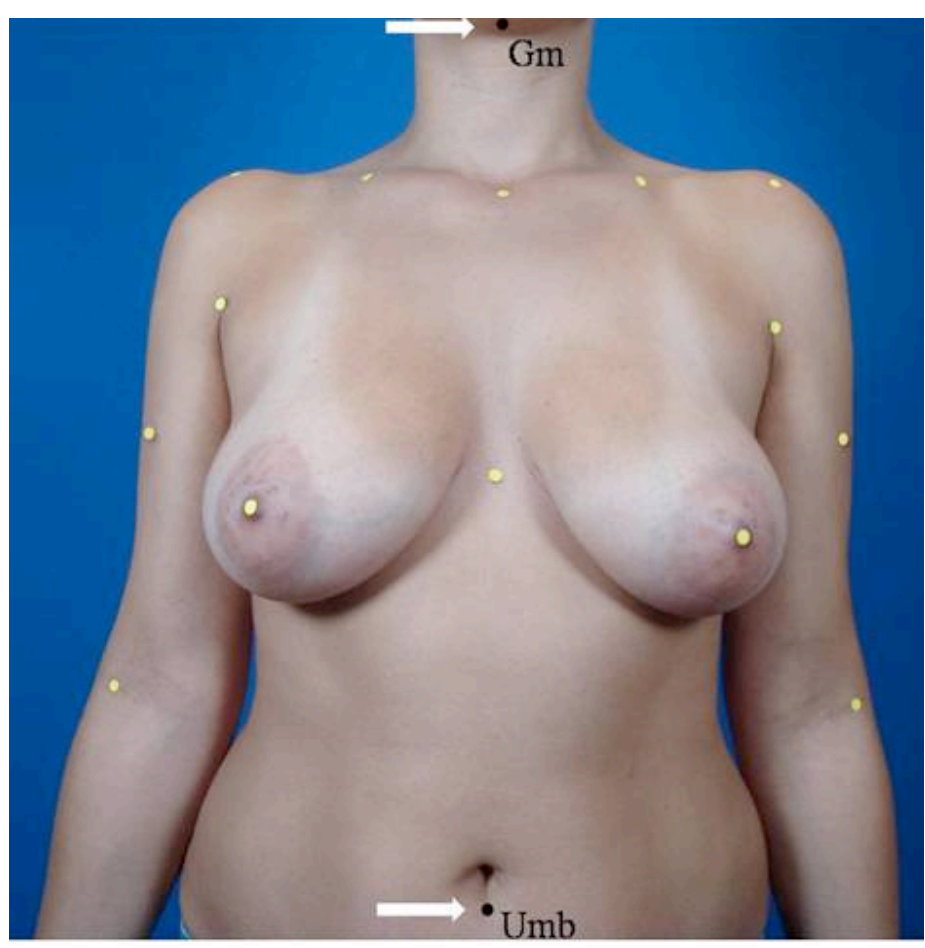

FIGURE 2 - Photo framing of the breast region. $\mathrm{Gn}$ = gnathion; Umb = lower margin of the umbilicus.

\section{Results}

It was observed that the sagging breasts (ptosis) overlapped the lower and mid- points of the breast fold, blocking the view both in the anterior position (AP) and the profile view (Figure 3).

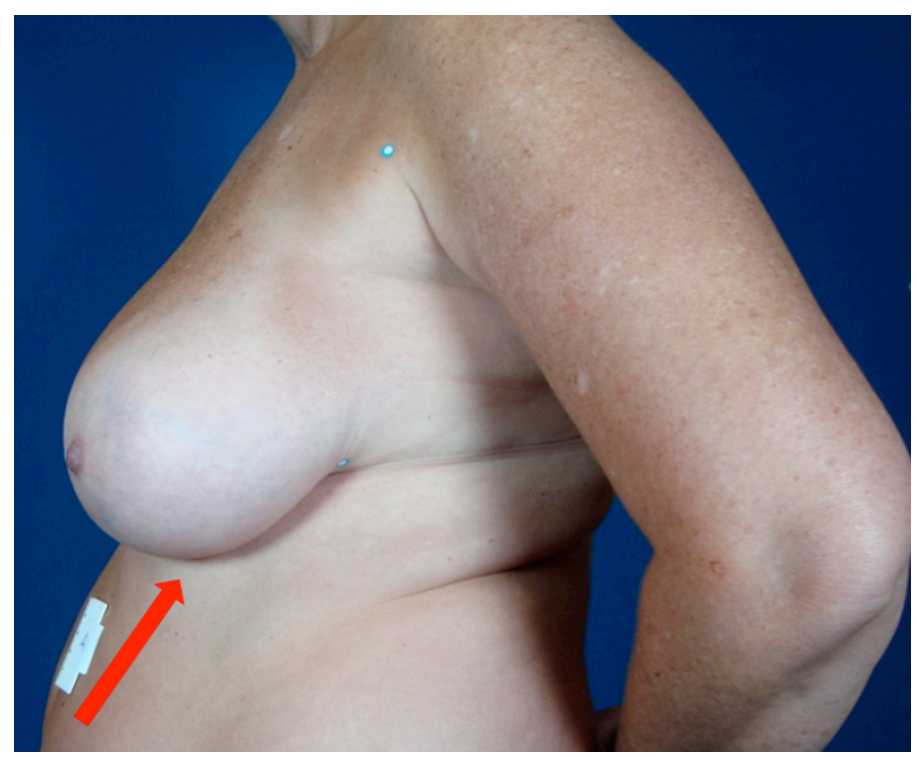

FIGURE 3 - Blocked view of the lower mid-point of the breast fold Profile photo image shows the blocked view of the breast fold. The arrow shows the blocked view of the mid-point of the breast fold. 
The precise point of the lateral extremity of the breast fold could not be determined in breasts with ptosis and in small breasts (Figure 4) (hypomastia) (Figure 5).

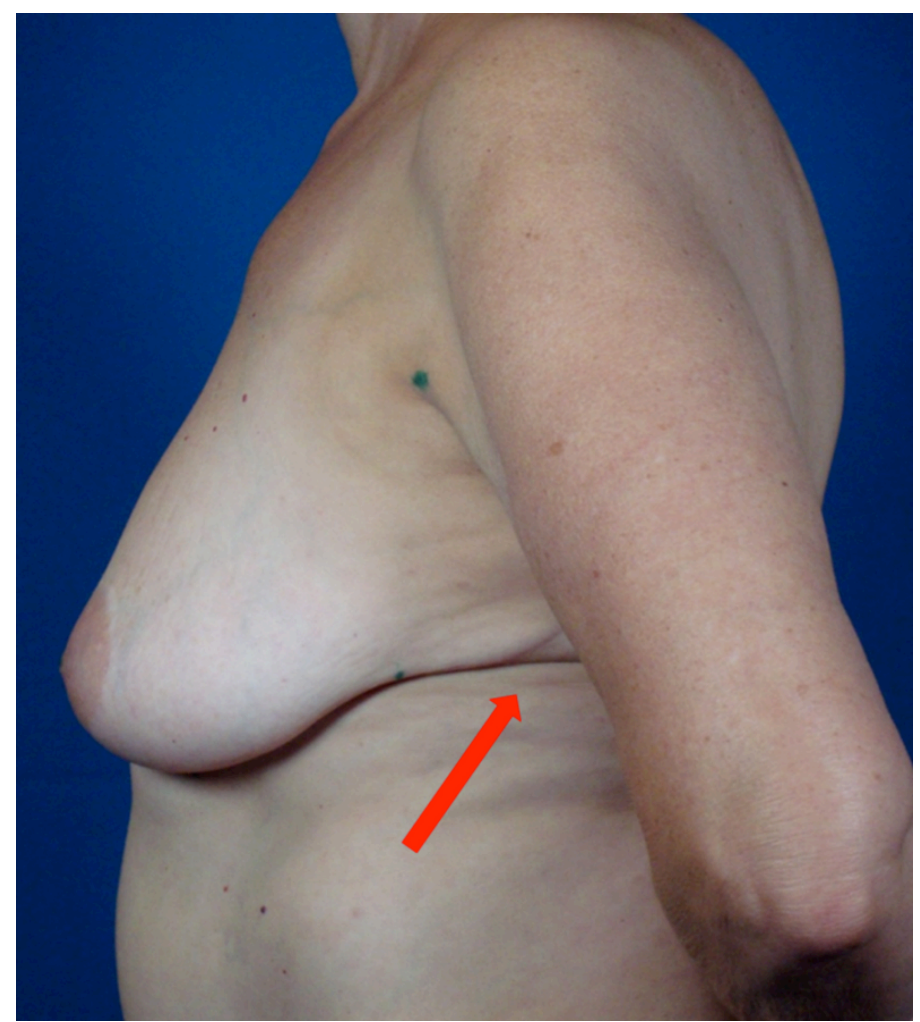

FIGURE 4 - Extension of the lateral point of the breast fold. The arrows show an extension beyond the anterior axillary line.

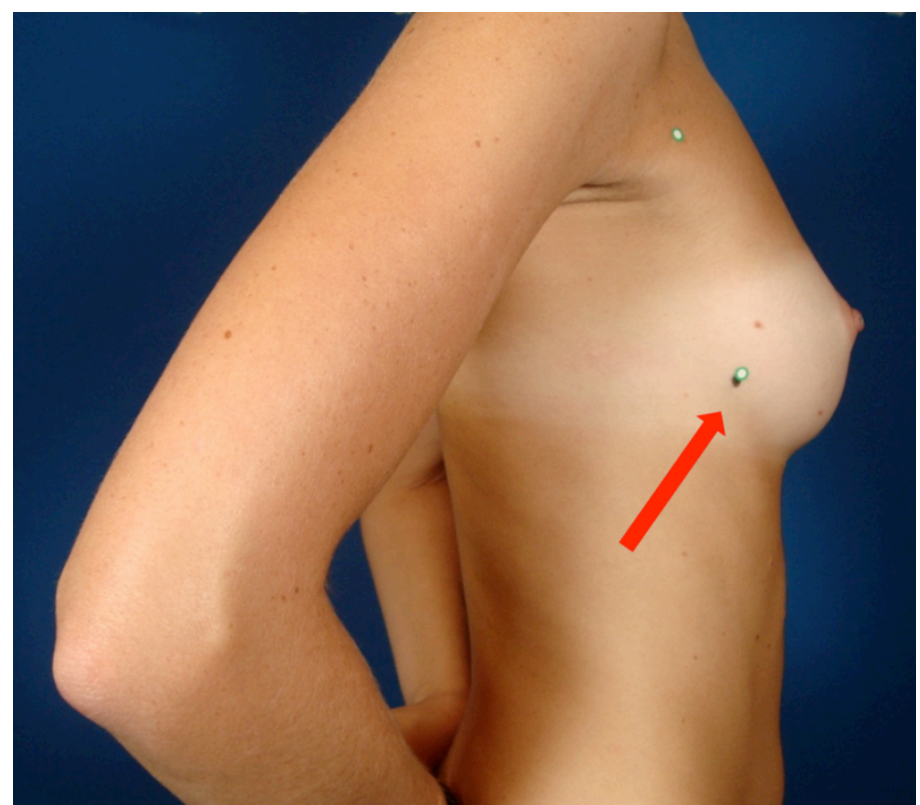

FIGURE 5 - Difficulty in determining the breast fold. Photo image shows the difficulty in visualizing the lateral extremity of the breast fold in a patient with hypomasty. The arrow shows the lateral portion of the breast fold.
The reference points of the umbilicus (Umb) and the pubis $(\mathrm{Pu})$ were also excluded, because these points did not show the correct position of the midline. The column and pelvis deviations changed the centralization of the midline. The best choice was to use the basis of the xiphoid process to mark the midline.

The use of self-adhesive labels to mark the anatomic points was considered a better choice compared to the use of a demographic pencil or a felt-tip pen (Figure 6). The analysis of photographs showed that some points marked with pen were of difficult visualization and caused discomfort to the patient, contrary to the use of self-adhesive labels.

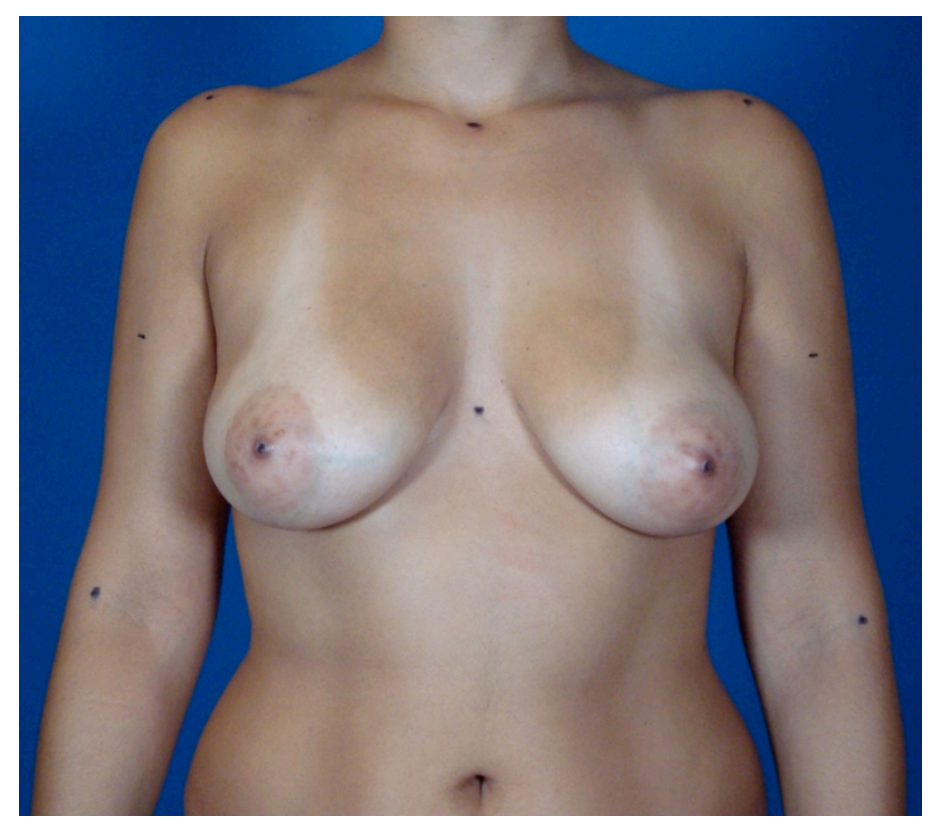

FIGURE 6 - Points marked with a pen. The image shows the difficulty in visualizing the marks made with a pen on the acromion and mammary papilla.

The following points were excluded: (a) the midline of the breast fold due to the difficulty in vizualizing the fold in a breast with ptosis, and (b) the lateral extremity of the breast fold due to the difficulty in vizualizing the fold in sagging and hypertrophic breasts.

\section{Discussion}

The systematization and standardization of photographic positions and angles and the use of markers on the anthropometric and/or anatomic landmarks can assure the reliability and reproducibility of a scientific study and are prerequisites for scientific publications ${ }^{3,25-28}$.

An objective evaluation of the breasts, which represent femininity, sensuality and motherhood, allows a 
better understanding of a woman's physical and mental health ${ }^{20}$. Penn ${ }^{6}$ was the precursor of the breast evaluation using direct anthropometry. He examined measurements in 20 female subjects who he described as having aesthetically perfect breasts. His objective was to find normal patterns of the breasts. Since then several authors have published articles in order to develop protocols for measuring the breasts using direct anthropometry ${ }^{4,7,9,16}$.

Liu and Thomson ${ }^{24}$ examined 109 volunteer women. Their main purpose was to determine the anthropometric measurements of the breasts, which could be aesthetically acceptable in cosmetic and reconstructive surgeries. The authors used photographic images in 5 different positions (front view, right and left oblique views and right and left sides). The images were then examined by a group of plastic surgeons, members of the American Society of Plastic Surgeons (ASPS), and patients of the Department of Plastic and Reconstructive Surgery at Yale School of Medicine. Neither the methods that were used for the measurement of the photographs nor the most appropriate positions for their analysis were mentioned in the article.

The use of graphics software in photograph measurements, which are static and do not require the physical presence of the individual in data collection, enables centesimal precision, reduces the possibility of errors and allows the evaluator to measure these photographs at different times, and is less intrusive and embarrissing for the patient ${ }^{4,8}$. These were the reasons that encouraged us to develop a study on breast measurement and whose results could be reproducible for future studies.

Odo et al. ${ }^{10}$ have analyzed preoperative and postoperative results of mammary asymmetry using direct anthropometry. In comparative studies on surgeries to correct breast asymmetry, Pozzobon et $a l .{ }^{20}$ have used nuclear magnetic resonance (NMR) and linear measurements in breasts.

As there is no consensus on the points that can be used for breast measurements, neither the ideal instrument for this evaluation, we decided to do some research on a reproducible and accurate tool for this procedure.

The volunteers with previous history of any type of surgery on the breasts and/or thoracic deformities were excluded to minimize any possible interference in the study, as these deformities could cause distortions during the measurements made with the use of direct anthropometry. Also not included were the women whose breast sizes exceeded the line below the umbilicus, and therefore, would exceed the photographic framing used in this study.

To determine the anatomic and anthropometric points to be used for the breast measurements in the present study, we analyzed the literature of the last 56 years. Seventeen articles that associated the use of direct anthropometry for the measurements of the breasts with the anthropometric and anatomic points were selected.

According to Westreich ${ }^{8}$, the segment of the axilla to the center of the mammary papilla and the lateral point of the breast fold make accurate measurements of this organ very difficult, because the landmarks made on the soft tissue structures do not remain constant over time. These measurements may vary quite a bit from woman to woman and be even altered by any movement made by the patient, therefore, the results could be inaccurate. The author has excluded any landmarks made on soft tissue structures from his study.

Smith et al. ${ }^{14}$ found 15 to $20 \%$ of differences in measurements, where the measurement started in the reference point of the anterior axillary line to any other point of reference on the chest. The authors concluded that any minimal changes of the patient's position would change these measurements assessed by direct anthropometry. In this specific case, the measurements were made using a photographic image, and therefore, they were not affected by the patient's positions or breathing movements of the chest.

Considering all the points and measurements selected from the articles, the present study evaluated five volunteers to determine the feasibility of using photogrammetry as an alternative assessment tool. These points were marked on the skin surface, and after, the volunteers were photographed in a standing position. Some breasts overlapped the point marked in the lower and midportion of the breast fold, obstructing the vizualization of the selfadhesive labels in AP and profile views.

It was not possible, for example, to precisely locate the point on the lateral extremity of the breast fold in breasts with large lateral extension in AP and profile views. In small breasts (hypomasty), this point was also difficult to be precisely determined because the breast fold did not have a well defined contour. Thus, only the points and measurements described earlier in this study were used, except the profile view. For the study on the use of photographs, some authors used photographic images in 5 different positions (front view, right and left oblique views and right and left sides $)^{3,8,28}$. In our study, we suggest the use of AP position because the points in oblique and profile views are not visible within the precise limits of the photographic documentation of the breast. The upper line of the photographic framing was delimited by the gnathion and the lower line by the bottom margin of the umbilicus, according to Hochman et al. ${ }^{3}$. 
Several authors have attempted to standardize photographs for clinical evaluation, however, the variability remains a challenge $\mathrm{e}^{3,28-31}$.

No measurements of the profile were obtained, therefore, the choice made for the anatomic position was that less subject to bias, since it is well known in anthropometric studies.

The standardization of the photographic framing, the distance and the height of camera and spotlights, the patient positioning are required for subsequent evaluations, such as the comparisons between pre and post- operative procedures to allow valid comparisons between techniques and results, preserving the scientific rigor ${ }^{27}$. Obtaining linear measurements from photographs rather than directly from the individual has proved to be another effective way to evaluate the breasts ${ }^{32}$. Accordding to Nechala et $a l .{ }^{4}$, photogrammetry has advantages over direct anthropometry. The use of graphics software in photograph measurements, which are static and do not require the physical presence of the individual in data collection, enables centesimal precision, reduces the possibility of errors and allows the evaluator to measure these photographs at different times, and is less intrusive and embarrissing for the patient. A photograph is quicker and more efficient and can be examined immediately after they were taken. It does not require specific technical training and is cheaper compared to 3Ds scanners.

Lighting is an extremely important resource to preserve the technical accuracy of clinical photographs. Excessive lighting or light overexposure can mask folds, wrinkles or scars. Similarly, poor lighting or underexposure may cause obscuring shadows and enhanced wrinkles or scars ${ }^{33}$. In the present study, 2 light diffusers were connected to the Photo-Flood lamps. Each difuser was placed at a 45 degree angle to the photographic background. The adequate lighting provided photographs without shadows and a proper measurement of the breasts.

To standardize the distance between the feet and the background, a mold was made using $1 \mathrm{~cm}$ thickness EVA foam, in purple, to maintain the volunteer's positioning $70 \mathrm{~cm}$ from the background with a $30 \mathrm{~cm}$ distance between the feet, as suggested by DiBernardo et $a l .{ }^{30}$.

There is a particular similarity between direct anthropometry and photogrammetry related to some body segments (head, face, eyes, nose, mouth and ears) ${ }^{4}$, contrary to the breast region. This can be explained by the fact that no formula has been found yet to identify the actual measurements based on those obtained by indirect anthropometry. Quieregatto et al. ${ }^{34}$ demonstrated that direct and indirect anthropometry with three different software to the breast region, did not present correlation between them. ${ }^{34}$ Therefore, the design used in this study suggests that its possible measurements in the breast region and can guarantee the analysis and reproducibility for further publications.

The present study has showed that the use of photographic images of the breasts cannot be used indiscriminately. Some parameters should be established to measure the breasts especially in studies that evaluate these organs in two different time periods (e.g. pre and post operatively) and the same image framing and points should be used in both periods.

\section{Conclusion}

The frontal view photographs of the patient's breasts is better when compare with the lateral positions, and can be used for an universal types of breasts with this points described. The following points: mid-portion of the breast fold, lateral portion of the breast fold, umbilicus (Um) and pubis $(\mathrm{Pu})$ points should not be used for photogrammetry of any type of breast size and shapes.

\section{References}

1. Christie D, Sharpley C, Curtis T. Improving the accuracy of a photographic assessment system for breast cosmesis. Clin Oncol (R Coll Radiol). 2005 Feb;17(1):27-31. PMID: 15714926.

2. Ellis H, Colborn GL, Skandalakis JE. Surgical embryology and anatomy of the breast and its related anatomic structures. Surg Clin North Am. 1993 Aug;73(4):611-32. PMID: 8378813.

3. Hochman B, Nahas FX, Ferreira LM. Photography in medical research. Acta Cir Bras. 2005;20 Suppl 2:19-25. PMID: 16283023.

4. Nechala P, Mahoney J, Farkas LG. Digital two-dimensional photogrammetry: a comparison of three techniques of obtaining digital photographs. Plast Reconstr Surg. 1999 Jun;103(7):1819-25. PMID: 10359240.

5. Watmough DJ. Diaphanography: mechanism responsible for the images. Acta Radiol Oncol. 1982;21(1):11-5. PMID: 6283792.

6. Penn J. Breast reduction. Br J Plast Surg. 1955 Jan;7(4):357-71. PMID: 13230442.

7. Smith DJ Jr, Palin WE Jr, Katch V, Bennett JE. Surgical treatment of congenital breast asymmetry. Ann Plast Surg. 1986 Aug;17(2):92101. PMID: 3273092.

8. Westreich M Anthropomorphic breast measurement: protocol and results in 50 women with aesthetically perfect breasts and clinical application. Plast Reconstr Surg. 1997 Aug;100(2):468-79. PMID: 9252618.

9. Brown TP, Ringrose C, Hyland RE, Cole AA, Brotherston TM. A method of assessing female breast morphometry and its clinical application. Br J Plast Surg. 1999 Jul;52(5):355-9. PMID: 10618977.

10. Odo LM, Guimarães PA, Silva AL, Sabino Neto M, Ferreira LM. Assessing the outcome of surgical treatment of breast asymmetry by means of linear measures. Arq Catarinenses Med. 2009;38(Suppl 1):43-5.

11. Quieregatto PR, Hochman B, Ferrara SF, Furtado F, Liebano RE, Sabino Neto M, Ferreira LM. Anthropometry of the breast region: how to measure? Aesthetic Plast Surg. 2014 Apr;38(2):3449. PMID: 24610111.

12. Sivagnanavel V, Smith RT, Lau GB, Chan J, Donaldson C, Chong 
NV. An interinstitutional comparative study and validation of computer aided drusen quantification. Br J Ophthalmol. 2005 May;89(5):554-7. PMID: 15834083.

13. Assunção WG, Gomes EA, Tabata LF, Gennari-Filho H. A comparison of profilometer and AutoCAD software techniques in evaluation of implant angulation in vitro. Int J Oral Maxillofac Implants. 2008 Jul-Aug;23(4):618-22. PMID: 18807556.

14. Smith DJ Jr, Palin WE Jr, Katch VL, Bennett JE. Breast volume and anthropomorphic measurements: normal values. Plast Reconstr Surg. 1986 Sep;78(3):331-5. PMID: 3737757.

15. Loughry CW, Sheffer DB, Price TE, Einsporn RL, Bartfai RG, Morek WM, Meli NM. Breast volume measurement of 598 women using biostereometric analysis. Ann Plast Surg. 1989 May;22(5):380-5. PMID: 2729845.

16. Malata CM, Boot JC, Bradbury ET, Ramli AR, Sharpe DT. Congenital breast asymmetry: subjective and objective assessment. Br J Plast Surg. 1994 Mar;47(2):95-102. PMID: 8149066.

17. Qiao Q, Zhou G, Ling Y. Breast volume measurement in young Chinese women and clinical applications. Aesthetic Plast Surg. 1997 Sep-Oct;21(5):362-8. PMID: 9299007.

18. Sigurdson LJ, Kirkland SA. Breast volume determination in breast hypertrophy: an accurate method using two anthropomorphic measurements. Plast Reconstr Surg. 2006 Aug;118(2):313-20. PMID: 16874195.

19. Denoel C, Aguirre MF, Bianco G, Mahaudens PH, Vanwijck R, Garson S, Sinna R, Debrun A. Idiopathic scoliosis and breast asymmetry. J Plast Reconstr Aesthet Surg. 2009 Oct;62(10):1303-8 PMID: 18701363.

20. Pozzobon AV, Sabino Neto M, Veiga DF, Abla LE, Pereira JB, Biasi TL, Ferreira LM, Yamashita LA, Kawano F, Nakano EM, Shigueoka DC. Magnetic resonance images and linear measurements in the surgical treatment of breast asymmetry. Aesthetic Plast Surg. 2009 Mar;33(2):196-203. PMID: 18709409.

21. Vandeput JJ, Nelissen M. Considerations on anthropometric measurements of the female breast. Aesthetic Plast Surg. 2002 SepOct;26(5):348-55. PMID: 12432473.

22. Kim MS ${ }^{1}$, Reece GP, Beahm EK, Miller MJ, Atkinson EN, Markey MK. Objective assessment of aesthetic outcomes of breast cancer treatment: measuring ptosis from clinical photographs. Comput Biol Med. 2007 Jan;37(1):49-59. PMID: 16438948.

23. Agbenorku P, Agbenorku M, Iddi A, Amevor E, Sefenu R, Osei D. Measurements of breasts of young West African females: a guideline in anatomical landmarks for adolescent breast surgery. Aesthetic Plast Surg. 2011 Feb;35(1):49-54. PMID: 20665021.

24. Liu YJ, Thomson JG. Ideal anthropomorphic values of the female breast: correlation of pluralistic aesthetic evaluations with objective measurements. Ann Plast Surg. 2011 Jul;67(1):7-11. PMID: 21301308.

25. Farkas LG, Bryson W, Klotz J. Is photogrammetry of the face reliable? Plast Reconstr Surg. 1980 Sep;66(3):346-55. PMID: 7422721

26. McCausland TM. A method of standardization of photographic viewpoints for clinical photography. J Audiov Media Med. 1980 Jul;3(3):109-11. PMID: 7299046.

27. Rodrigues OR, Geraldelli S, Minamoto H, Schmidt AF Jr. A fotografia em ciências biológicas: uso no ensino e na documentação científica. Acta Cir Bras 1995;10(4):173-82.

28. Gherardini G, Matarasso A, Serure AS, Toledo LS, DiBernardo BE. Standardization in photography for body contour surgery and suctionassisted lipectomy. Plast Reconstr Surg. 1997 Jul;100(1):227-37. PMID: 9207680.

29. Ellenbogen R, Jankauskas S, Collini FJ. Achieving standardized photographs in aesthetic surgery. Plast Reconstr Surg. 1990
Nov;86(5):955-61. PMID: 2236321.

30. DiBernardo BE, Adams RL, Krause J, Fiorillo MA, Gheradini G. Photographic standards in plastic surgery. Plast Reconstr Surg. 1998 Aug;102(2):559-68. PMID: 9703100.

31. DiSaia JP, Ptak JJ, Achauer BM. Digital photography for the plastic surgeon. Plast Reconstr Surg. 1998 Aug;102(2):569-73. PMID: 9703101.

32. Sacchini V, Luini A, Tana S, Lozza L, Galimberti V, Merson M, Agresti R, Veronesi P, Greco M.Quantitative and qualitative cosmetic evaluation after conservative treatment for breast cancer. Eur J Cancer. 1991;27(11):1395-400. PMID: 1835855.

33. Jakowenko J.Clinical photography. JTelemed Telecare. 2009; 15(1):722. PMID: 19139215.

34. Quieregatto PR, Hochman B, Furtado F, Machado AF, Sabino Neto $\mathrm{M}$, Ferreira LM. Image analysis software versus direct anthropometry for breast measurements. Acta Cir Bras. 2014 Oct;29(10):688-95. PMID: 25318002.

\section{Correspondence:}

Miguel Sabino Neto

Departamento de Cirurgia Plástica - UNIFESP

Rua Napoleão de Barros, $715 / 4^{\circ}$ andar

04023-002 São Paulo - SP Brasil

Tel.: (55 11)5576-4118

Fax: (55 11)5539-0824

msabino@uol.com.br

Received: March 8, 2015

Review: May 11, 2015

Accepted: June 10, 2015

Conflict of interest: none

Financial source: none

${ }^{1}$ Research performed at Division of Plastic Surgery, Department of Surgery, Universidade Federal de São Paulo (UNIFESP), Brazil. Part of Master degree thesis, Postgraduate Program in Translational Surgery, UNIFESP. Tutor: Bernardo Hochman. 